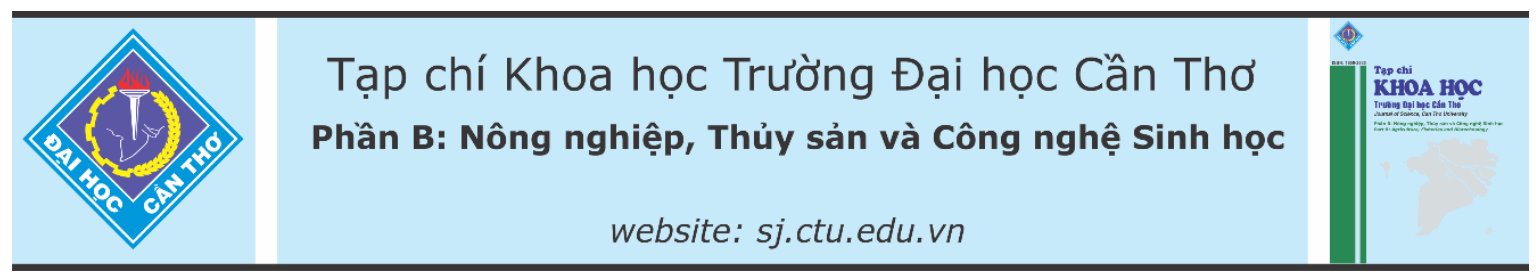

DOI:10.22144/ctu.jvn.2021.092

\title{
KHÁC BIẸT VỀ Hệ PHIÊN MÃ DƯỚI TÁC ĐỘNG CỦA MẶN LÊN 2 GIỐNG LÚA MÙA Ở GIAI ĐOẠN CÂY CON
}

Huỳnh Kỳ ${ }^{1 *}$, Văn Quốc Giang ${ }^{1}$, Nguyễn Văn Mạnh ${ }^{1}$, Trần In Đô ${ }^{1}$, Nguyễn Thành Tâm $^{2}$, Nguyễn Châu Thanh Tùng ${ }^{1}$ và Nguyễn Lộc Hiền ${ }^{1}$

${ }^{1}$ Bộ môn Di truyền và Chọn giống Cây trồng, Khoa Nông nghiệp, Trương Đại học Cần Tho

${ }^{2}$ Viện Nghiên cưu Phát triển Đồng bằng sông Cửu Long, Truờng Đại học Cần Tho

*Nguoòi chịu trách nhiệm về bài viết: Huỳnh Kỳ (email: hky@ctu.edu.vn)

\section{Thông tin chung:}

Ngày nhận bài: 06/12/2020

Ngày nhận bài sủa: 07/01/2021

Ngày duyệt đăng: 25/06/2021

\section{Title:}

Differential gene expression under salt stress at seedling stage as response of Doc Phung and nep Mo varieties

\section{Tù khóa:}

Đốc Phưng, hệ gen biểu hiện, mặn, nếp Mõ, OsDREB

\section{Keywords:}

Doc Phung, nep Mo, Salt, Transcriptome, OsDREB

\begin{abstract}
Climate change has seriously affected people's lives and agricultural production in the Mekong Delta, of which saline intrusion is one of the main factors affecting agricultural productivity. Therefore, it is very urgent to study the transcriptome of salt-tolerant rice varieties representing the Mekong Delta. In this study, Doc Phung (salt tolerant) and nep Mo (salt sensitive) varieties were used to treat with $100 \mathrm{mM}$ of $\mathrm{NaCl}$ for 12 hours at 14 days of seedling, the treated samples were collected and isolated total RNA for further analysis. The results showed that the total unique transcripts in Doc Phung (1596 genes) were more genes expressed than in Nep Mo (427 genes), and most of the transcripts in the two salected varieties responded to saline stress related to GO response to stimulus. These results showed that OsBREB family gene was candidated involving in the salinity stress, and can be used for further research.
\end{abstract}

\section{TÓM TẮT}

Biến đổi khi hậu đã và đang ảnh hưởng nghiêm trong đến đời sống nguời dân và sản xuất nông nghiệp vùng Đồng bằng Sông Cửu Long, trong đó xâm nhiếm mặn là một trong nhũng yếu tố tác động chính lên sản luợng nông nghiệp. Do đó, việc tìm ra hệ gien biểu hiện ở các giống lúa chống chịu mặn đại diện cho vùng Đồng bằng Sông Cưu Long là cấp thiết. Ở nghiên cứu này giống Đốc Phưng đại diện cho kiểu gien chống chịu stress mặn, nếp Mõ đại diện cho kiểu gen mẫn cảm stress mặn, 2 giổng lúa được chọn cho nảy mầm và 14 ngày sau nảy mầm, cây con được xủ lý muối $\mathrm{NaCl}$ ơ nồng độ $100 \mathrm{mM}$ cho 12 giờ, mẫu sau khi xử lý stress mặn được thu thập và ly trích RNA. Kết quả phân tích hệ gien biểu hiện cho thấy giống Đốc Phưng (1596 gen) có số luợng gen biểu hiện nhiều hơn giống nếp Mõ (427 gen), và hầu hết các gen ở hai giống thí nghiệm đều phản ưng tới stress mặn liên quan đến chức năng kich thich phản ứng bởi stress. Kết quả này bước đầu đã chọn ra được các gien liên quan đển phản ứng stress mặn nhu ho gien OsDREB, và có thể dùng tiếp cho nghiên cúu chuyên sâu hơn. 


\section{1. ĐẶT VẤN ĐỀ}

Theo Cơ quan quản lý thiên tai Việt Nam (VNDMA, 2020) thuộc bộ Nông nghiệp và Phát triển Nông thôn, biến đổi khi hậu đã tác động mạnh đến Việt Nam nói chung và Đồng bằng Sông Cửu Long (ĐBSCL) nói riêng, thiệt hại do xâm nhiễm mặn và hạn hán đã đã ảnh hưởng đến 71.656 ha lúa, 93 ha hoa màu và 762 ha cây ăn trái (tính cho đến ngày 27 tháng 07 năm 2020), và được dự đoán thiệt hại sẽ gia tăng ở những năm tới. Thêm vào đó, ước tính năm 2007 thế giới đã tiêu thụ khoản hơn 19.055 tấn gạo (CGIAR) và theo tổng kết 10 năm tiêu thụ gạo ước tính khoản 22.000 tấn (USDA, 2018). Để giải quyết vấn đề này, việc cải thiện năng suất lúa là rất quan trọng đối với an ninh lương thực, tăng trưởng kinh tế và nông nghiệp bền vững. Đứng trước thực trạng đó, các nhà khoa học Việt Nam đã và đang nghiên cứu chọn tạo các giống lúa có khả năng thích ứng trong điều kiện xâm nhiễm mặn, nhằm đảm bảo an ninh lương thực.

Để có thể sinh trưởng và phát triển được trong môi trường stress mặn, cây lúa cần thực hiện một số cơ chế sinh lý khác nhau như loại bỏ muối ở rễ, vận chuyển natri từ rễ đến chồi và một cơ chế khác để lưu trữ ion natri trong các mô và không bào (Shannon, 1985; Yeo \& Flowers, 1986). Để vận hành được các cơ chế đó, cây lúa phải trãi qua quá trình phiên mã các hệ gien liên quan đến các cơ chế chống chịu mặn khi có sự tác động của mặn. Được biết ở giai đoạn cây con, cây lúa rất mẫn cảm với mặn vì vậy nghiên cứu về hệ gien biểu hiện ở giai đoạn cây con liên quan đến khả năng chịu mặn ở các giống lúa chịu mặn đã được rất nhiều nghiên cứu như trên lúa hoang Dongxiang (Oryza rufipogon Griff) (Zhou et al. 2016), giống lúa Chibo (Chandran et al. 2019), giống lúa Xian156 (Wang et al. 2018), và một trong những giống lúa được xem là chuẩn chống chịu mặn được rất nhiều nghiên cứu về mặn là Pokkali (Li et al. 2018). Trong khuôn khổ của nghiên cứu này, đã ứng dụng kỹ thuật nghiên cứu hệ gien biểu hiện ở giai đoạn cây con của giống lúa chịu mặn địa phương của ĐBSCL được thực hiện nhằm tìm ra các gien có phản ứng sớm liên quan đến khả năng chống chịu mặn. Kết quả nghiên cứu này là tiền đề giúp chọn tạo ra các giống lúa chống chịu mặn phục vụ cho ĐBSCL trong tương lai.

\section{VÂT LIÊUU VÀ PHƯỚNG PHÁP NGHIẾN CÚU}

\subsection{Vật liệu nghiên cứu}

Theo nghiên cứu của (Tam 2019), giống Đốc Phụng chống chịu mặn tốt, và giống nếp Mỡ là đại diện cho giống mẫn cảm với mặn và hai giống này là giống lúa mùa của $Đ B S C L$ và cùng hệ gen indica. Do đó, trong nghiên cứu này giống Đốc Phụng (ĐP) là giống chống chịu mặn và giống nếp $\mathrm{M}$ ơ $(\mathrm{NM})$ là giống mẫn cảm với mặn, cả hai giống được thu thập tại ĐBSCL và hiện đang lưu giữ tại ngân hàng gen, Trường Đại học Cần Thơ.

\subsection{Phương pháp nghiên cứu}

\subsubsection{Xử lý stress mặn}

Hạt giống lúa Đốc Phụng và nếp Mỡ sau khi được lấy từ kho lạnh được để ở nhiệt độ phòng cho 24 giờ sau đó được ngâm trong nước cất trong bóng tối, và các hạt nảy mầm đồng đều được gieo trong hộp nhựa. Để dùng cho nghiên cứu hệ gen biểu hiện giai đoạn sớm của cây con (RNA-seq), cây con 14 ngày tuổi được xử lý mặn ở nồng độ $100 \mathrm{mM} \mathrm{NaCl}$ (nồng độ mặn tương đương 6\%) và $0 \mathrm{mM} \mathrm{NaCl}$ (đối chứng) trong dung dịch dinh dưỡng Yoshida cho 12 giờ, sau đó toàn bộ phận của cây con (thân, lá và rễ được rửa sạch) được thu hoạch và làm đông ngay lập tức trong nitơ loãng, mẫu vật được tồn trữ ở $80^{\circ} \mathrm{C}$. Thí nghiệm được thực hiện trong điều kiện nhà kính có điều khiển nhiệt độ từ $26-33^{\circ} \mathrm{C}$, với thời gian chiếu sáng là 10 giờ sáng/ngày.

\subsubsection{Tách chiết RNA, chuẩn bị thu viện cDNA và giải trình tụ}

RNA tổng số được tách chiết từ các mẫu xử lý bằng cách sử dụng bộ RNeasy ${ }^{\circledR}$ Plant Mini theo hướng dẫn của nhà sản xuất (Qiagen, Đức). Định lượng và chất lượng RNA được kiểm tra bằng Nanodrop (Thermo) và Bioanalyzer 2100 (Agilent). $5 \mu \mathrm{g}$ RNA tổng số của mỗi mẫu được gửi đến BGI để giải trình tự RNA-seq bằng hệ thống Illumina 2500 Hiseq.

\subsubsection{Phân tích hệ gien biểu hiện (transcriptome)}

Đọc quá trình lọc và đánh giá biểu hiện gien khác biệt

Sau khi dữ liệu giải trình tự được xuất từ máy, dữ liệu được tiến hành kiểm soát chất lượng và xử lý trước các lần đọc đầu cuối, ghép nối thô được thực hiện bằng công cụ fastp V0.20.0, một bộ tiền xử lý FASTQ cực nhanh (Chen et al. 2018). Các lần đọc hệ phiên mã được so sánh lên hệ gien tham chiếu Os-Nipponbare-Reference-IRGSP-1.0 mới nhất (Kawahara et al. 2013), được xây trên cơ sở dữ liệu cây trồng (Ensembl Plants website) (Bolser et al. 2016) sử dụng using HISAT2 software V2.1.0 (Keel \& Snelling 2018; Kim et al. 2015), và những hệ gien biểu hiện được dò tìm trên hệ gien tham chiếu có chất lượng thấp $(\mathrm{MAPQ}<30)$ được loại bỏ bằng phần mềm SAMtool kits (Li et al. 2009). Để nhận 
dạng biến thể, các bản sao đã được xóa khỏi tệp gióng hàng bằng công cụ Picard V2.18.7 (http://broadinstitution.github.io/picard/). Sau đó, thực hiện sắp xếp lại xung quanh các chèn hoặc xóa (InDels) đã được xác định trong bước mục tiêu sắp xếp lại các InDel mục tiêu. Cả biến thể (SNPs) và chèn hoặc xóa (InDel) được phân tách bằng phần mềm SAMtool kits (Li et al. 2009) và BCFtools (Li 2011) bằng phiên bản mới nhất có tại Github (http://samtools.github.io/bcftools/bcftools.html\#ca 11). Tiếp tục phân tích hệ gien phiên mã, DESeq2 (Love et al. 2014) được sử dụng để tìm mức độ biểu hiện khác nhau ở các gien biểu hiện (Differentially Expressed Genes DEG) khi so sánh giữa mẫu đối chứng (không xử lý mặn) và mẫu xử lý mặn. Trước đó, số lần gien biểu hiện được tính bằng featureCounts (Liao et al. 2014), được tính là mức biểu hiện ban đầu với 1 gien được định vị trên bộ gien (gtf) có sẳn trên web (https://rapdb.dna. affrc.go.jp/download/irgsp1.html) dùng cho phân tích này. Các mức độ biểu hiện gien đã được tiêu chuẩn hóa bằng các cơ sở số lần đọc trên Kilo trên triệu lần đọc (RPKM). Ở bước này, những thay đổi lớn hơn 2 lần của mức độ biểu hiện có sự khác biệt có ý nghĩa $(\mathrm{P}<0,05)$ làm điều kiện để sàng lọc ý nghĩa của $\mathrm{DEG}$ giữa stress muối và mẫu đối chứng. Bước tiếp theo là các gien biểu hiện được phân nhóm theo chức năng của chúng (Gene Ontology [GO] enrichment analysis), phương pháp Singular Enrichment Analysis (SEA) được thực hiện nhờ phần mềm AgriGO V.2, với các mặc định cài đặc hệ số (False-Discovery Rate FDR) với hệ số giá trị p $<0.05$, trong phân tích này các gien được nhận dạng dựa vào các ID của gien tham chiếu trên lúa được ghi nhận trên NCBI (Tian et al. 2017).

\subsection{Thời gian và địa điểm nghiên cứu}

Nghiên cứu được thực hiện từ tháng 8 đến tháng 12 năm 2019 tại phòng thí nghiệm Di truyền và Chọn giống cây trồng, Khoa Nông nghiệp, Trường Đại học Cần Thơ.

\section{KẾT QUẢ VÀ THẢO LUẬN}

\subsection{Dữ liệu hệ gien được giải trình tự}

Nhằm tìm hiểu cơ chế chống chịu stress mặn của các giống lúa chịu mặn mùa đại diện cho ĐBSCL ở cấp độ phân tử, kỹ thuật RNA-seq giải trình tự hệ gien biểu hiện ở giai đoạn cây con được thực hiện. Trong nghiên cứu này hệ thống giải trình tự thế hệ mới (NGS) Illumina Hiseq 2500 được sử dụng đã đọc được tổng số hệ gien biểu hiện từ 66.985.319 67.291.969 ở giống Đốc Phụng, trong khi đó tổng số hệ gien được biểu hiện đọc được từ 65.736.921 66.836.598 ở nếp Mỡ, tương tự (Bảng 1). Ở phân tích này, bộ gien của giống Nipponbare được sử sụng làm hệ gien tham chiếu, trong đó hệ gien biểu hiện trong nghiên cứu này khi so với hệ gien tham chiếu thì số lần gien biểu hiện từ 58 triệu đến 60 triệu gien, trong khi đó số gien biểu hiện mà không tìm thấy được trong bộ gien tham chiếu từ 6 triệu đến 7 triệu gien. Chất lượng trung bình của hệ gien biểu hiện đều $>50 \%$, trong đó tỉ lệ $\mathrm{GC}>50 \%$ (Bảng 1), chứng tỏ số lần đọc được của hệ gien biểu hiện đủ chất lượng để tiếp tục cho phân tích tiếp theo (Zhou et al. 2016).

Bảng 1. Tóm tắt tổng số hệ gien phiên mã so sánh với bộ gien tham chiếu bằng hệ thống Illumina

\begin{tabular}{|c|c|c|c|c|}
\hline \multirow{2}{*}{ So sánh hệ gien tham chiếu } & \multicolumn{2}{|c|}{ Đốc Phụng 12 giờ sau xử lý } & \multicolumn{2}{|c|}{ Nếp Mõ̃ 12 giờ sau xử lý } \\
\hline & $\mathrm{O} \mathrm{mM} \mathrm{NaCl}$ & $100 \mathrm{mM} \mathrm{NaCl}$ & $\mathrm{O}$ mM NaCl & $100 \mathrm{mM} \mathrm{NaCl}$ \\
\hline $\begin{array}{l}\text { Tổng số hệ gien được đọc } \\
\text { (transcriptomes) }\end{array}$ & 66.985 .319 & 67.291 .969 & 66.836 .598 & 65.736 .921 \\
\hline $\begin{array}{l}\text { Tổng số hệ gien biểu hiện đọc được } \\
\text { so với bộ gien tham chểu }\end{array}$ & 59.762 .742 & 60.405 .527 & 60.229 .216 & 58.748 .296 \\
\hline $\begin{array}{l}\text { Tổng số hệ gien biểu hiện gien } \\
\text { không có trong bộ gien tham chiếu }\end{array}$ & 7.222 .577 & 6.886 .442 & 6.607 .382 & 6.988 .625 \\
\hline $\begin{array}{l}\text { Chất lượng trung bình khi so với bộ } \\
\text { gien tham chiếu }\end{array}$ & 58.78 & 58.77 & 58.77 & 58.75 \\
\hline Tỉ lệ GC & $51.36 \%$ & $51.06 \%$ & $51.33 \%$ & $51.45 \%$ \\
\hline
\end{tabular}

\subsection{Nhận diện mức độ biểu hiện khác nhau của hệ gien của mẫu sau xử lý mặn bằng RNA-seq}

Mức độ biểu hiện gien có thể được xác định từ dữ liệu trình tự Illumina đọc được dựa trên số lần đếm được ban đầu (Bloom et al. 2009). Khác biệt mức độ gien biểu hiện (DEG) được xác định trong các điều kiện kiểm soát và xử lý stress bằng muối để nhằm tìm ra sự khác biệt về hệ phiên khi so sánh giữa các giống mang kiểu chịu đựng và mẫn cảm ở 12 giờ sau khi xử lý muối $\mathrm{NaCl}$ ở nồng độ $100 \mathrm{mM}$. Nhìn chung, biểu đồ Venn cho thấy Đốc Phụng có 
1596 unigen biểu hiện khác biệt so với nếp Mỡ chỉ có 427 unigen (Hình 1).

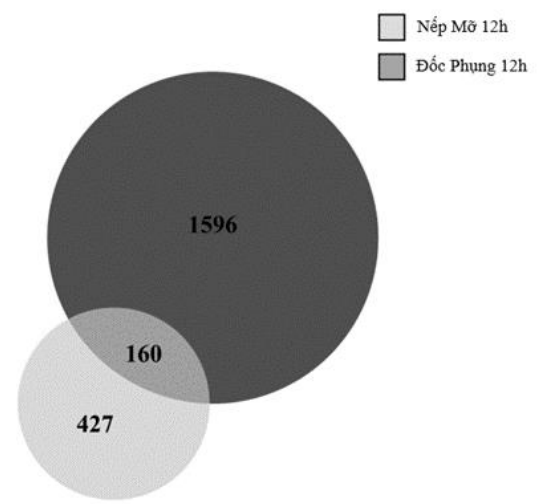

Hình 1. Biểu đồ Venn thể hiện unigen biểu hiện của giống Đốc Phụng và nếp Mõ̃ khi xử lý mặn $100 \mathrm{mM}$ ở thời điểm 12 giờ

\subsection{So sánh phân loại bản thể học gen (GO) của DEG trong 2 kiểu gen}

Khi phân tích bản thể học gien (GO) chỉ chon lọc các nhóm GO có ít nhất 3 gien biểu hiện trở lên và các gien đó phải có giá trị $\mathrm{P}<0.05$ mới được xếp nhóm và so sánh giữa Đốc Phụng và nếp Mỡ ở giai đoạn 12 giờ sau khi xử lý mặn, trong giai đoạn này hầu hết các $\mathrm{GO}$ đều được xếp vào trong 3 nhóm chính đó là thành phần tạo nên tế bào (cellular components), chức năng phân tử (molecular function) và quá trình sinh học (biological process). Nhìn chung tồng số gien biểu hiện ở ba nhóm chức năng của Đốc Phụng đều cao hơn nếp Mỡ khi gặp stress mặn, trong đó nhóm gien chức năng cấu phần tế bào, màng tế bào và nhóm gien mang chức năng phân tử biểu hiện cao nhất trong vai trò gắn kết các phân tử trong phản ứng hóa học. Trong khi đó chức năng quá trình sinh học nhóm gien được biểu hiện chỉ tập trung vào quá trình chất sinh hóa và quá trình tế bào (Hình 2). Trong khi nghiên cứu khả năng chụi mặn ở giống lúa Nhật Chilbo ở thời điểm 5 ngày sau xử lý mặn cho thấy hầu hết các nhóm gien biểu hiện đều thuộc trong chu trình tổng hợp chất sinh dưỡng (Metabolic process) (GO: GO:0006519) (Chandran et al. 2019)

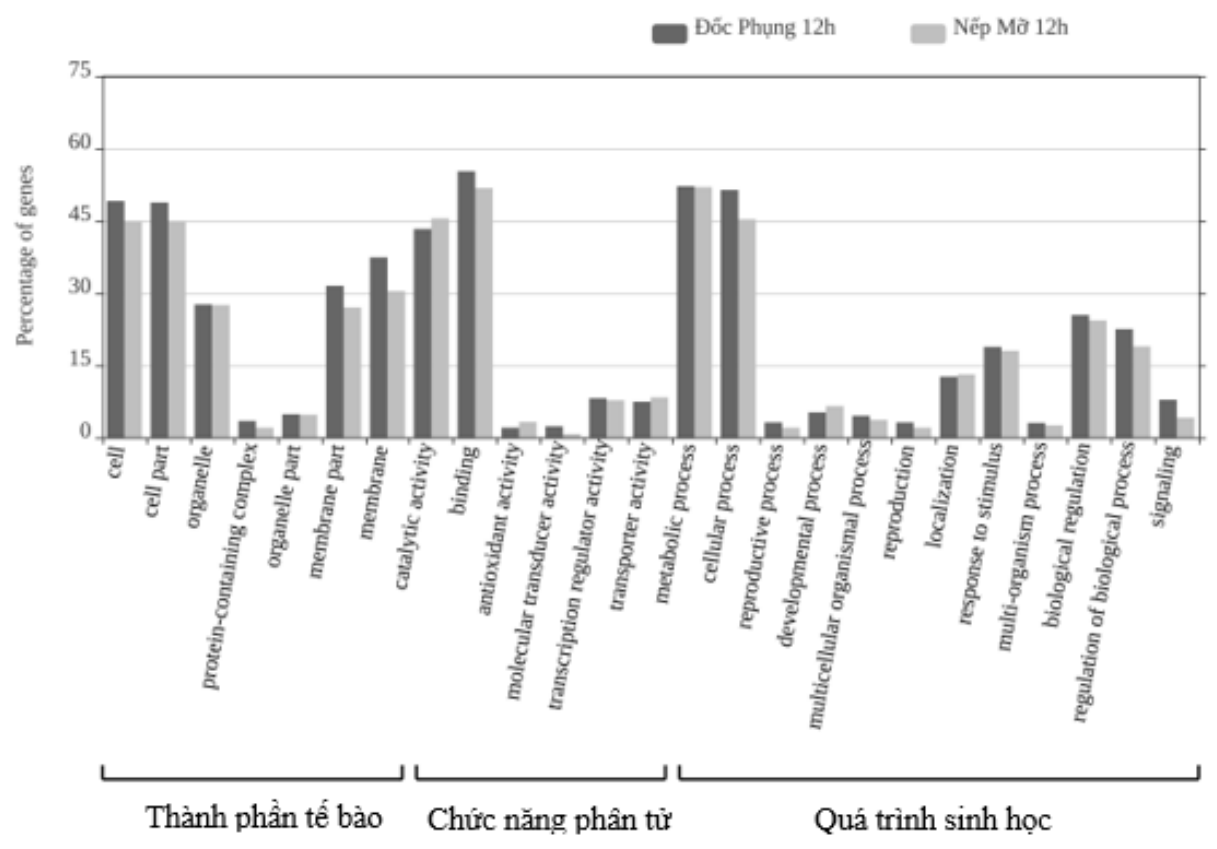

Hình 2. Nhóm gien biểu hiện được phân loại theo nhóm chức năng GO ở mẫu thí nghiệm.

\subsection{Phân tích chú giải bộ dữ liệu gen biểu hiện theo chức năng GO}

Biểu đồ bong bóng cho thấy khác biệt ở mỗi giống có nhóm gen chức năng chuyên biệt phản ứng với stress sau khi xử lý muối với $100 \mathrm{mM} \mathrm{NaCl}$ ở thời điểm 12 giờ (Hình 3). Đối với giống lúa Đốc
Phụng hầu hết các hệ gen biểu hiện giảm có ý nghĩa đều tập trung vào tiến trình sinh học với nhóm chức năng phản ứng kích hoạt (GO term: response to stimulus) và giảm sự biểu hiện nhiều nhất thuộc vào nhóm gen có chức năng phân tử, đặc biệt là nhóm gen liên quan đến yếu tố phiên mã (GO term: molecular function), ngược lại giống mẫn cảm với 
mặn NM hầu hết các nhóm gien biểu hiện đều tăng và đều thuộc vào nhóm tiến trình sinh học với nhóm chức năng phản ứng kích hoạt (GO term: response to stimulus). Điều đó chứng tỏ mỗi kiểu gien khác nhau sẽ có phản ứng với stress mặn khác nhau và điều này giống như nghiên cứu trước đây (Hussain et al. 2019; Li et al. 2018).

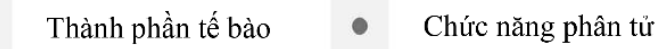
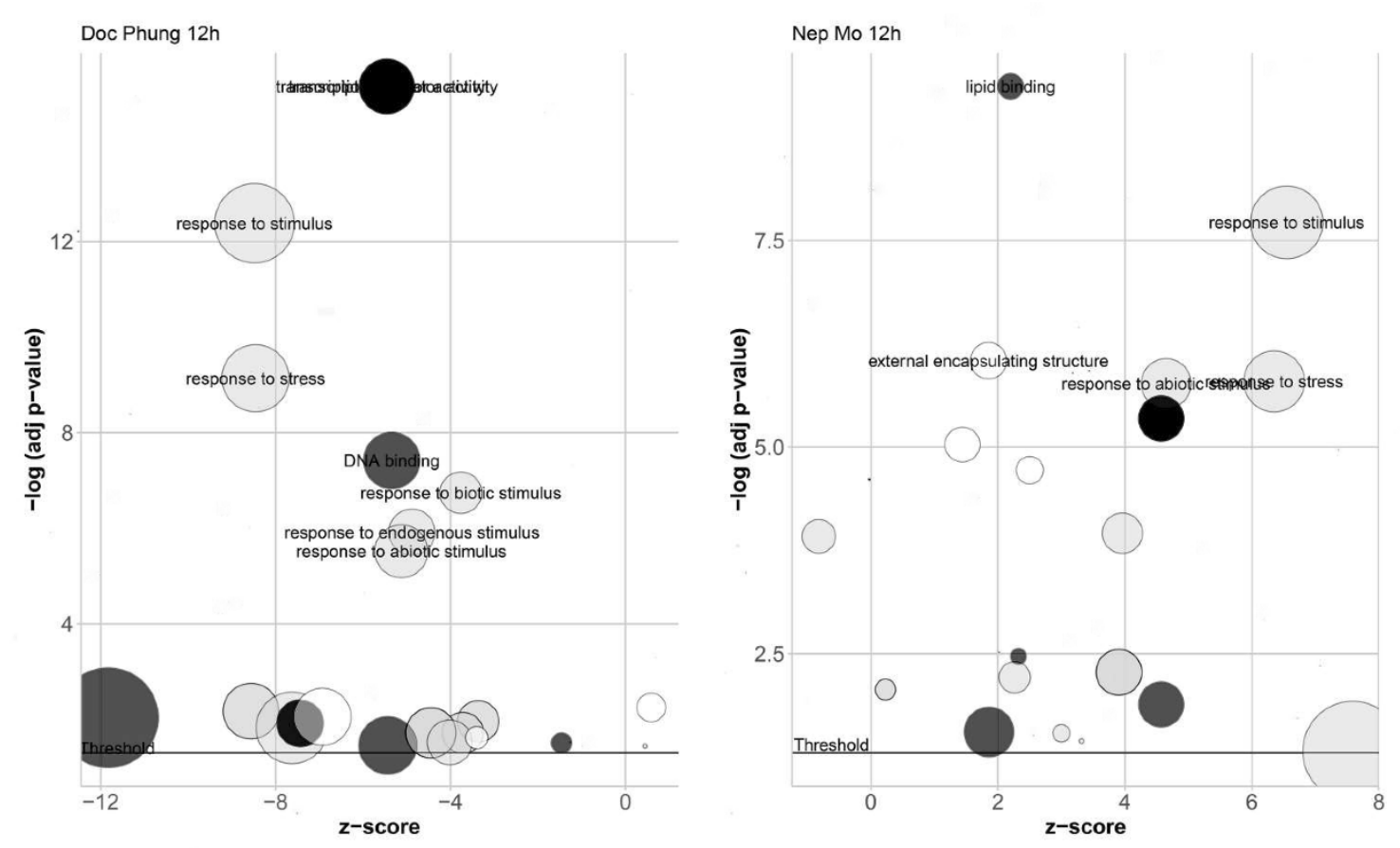

\section{Hình 3. Biểu đồ bong bóng thể hiện các nhóm chức năng biểu hiện tăng và giảm khi xử lý mặn ở nồng độ muối NaCl $100 \mathrm{mM}$ vào thời điểm 12 giờ sau khi xử lý}

Thêm vào đó, dựa vào nhóm unigen được phân nhóm chức năng theo biểu đồ bong bóng, nhóm gien biểu hiện chức năng sinh học được phân tích mối liên kết đơn bằng phương pháp Singular Enrichment Analysis (SEA) được cung cấp bởi AgriGo V2 (Tian et al. 2017), phân tích này dựa vào bộ cơ sở dữ liệu 25.465 gen chức năng được công bố trên MSU Rice Genome Annotation (Kawahara et al. 2013). Nhìn chung cả Đốc Phụng và nếp Mỡ khi bị xử lý stress mặn điều biểu hiện nhóm gien chức năng liên quan đến quá trình sinh học tuy nhiên mức độ biểu hiện của hai kiểu gen khác nhau và điều liên quan đến chức năng phản ứng kích thích của stress
(GO:0050896) và cuối cùng là đi đến nhóm gen phản ứng với stress (GO: 0006950) (Hình 4). Tuy nhiên, mức độ phản ứng lại stress mặn ở hai kiểu gien có khác nhau. Tóm lại các gien biểu hiện có ý nghĩa trong nghiên cứu này khi gặp stress mặn điều liên quan đến nhóm gien yếu tố phiên mã và các chuyển hóa sinh học (Bảng 2 ). Kết quả này cũng tương tự như những nghiên cứu trước cho thấy yếu tố phiên mã đều liên quan trực tiếp đến phản ứng stress phi sinh học như hạn mặn như họ gien $D R E B$ (Moon et al. 2019; Shinozaki \& YamaguchiShinozaki 2006; Wang et al. 2008) 


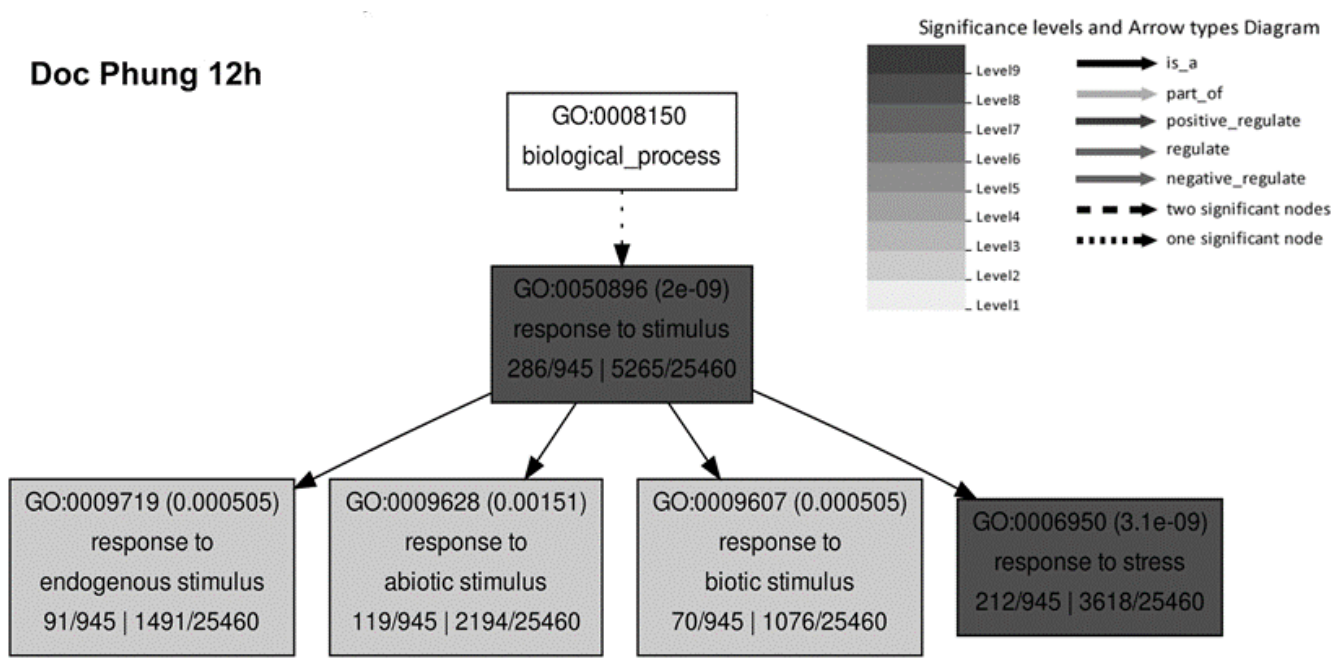

\section{Nep Mo $12 \mathrm{~h}$}

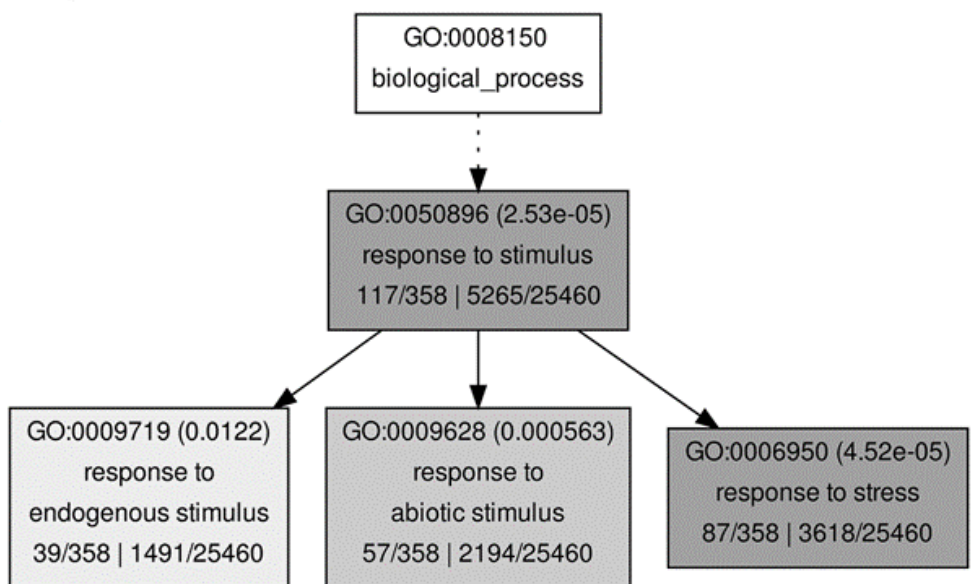

Hình 4. Phân tích Singular Enrichment Analysis (SEA) của ĐP và NM khi xử lý mặn ở nồng độ muối $\mathrm{NaCl} 100 \mathrm{mM}$ vào thời điểm 12 giờ sau khi xử lý

Bảng 2. Danh sách các gen được biểu hiện của Đốc Phụng và nếp Mỡ tại thời điểm 12 giờ sau xử lý 100 mM NaCl

\begin{tabular}{|c|c|c|c|c|c|}
\hline \multicolumn{3}{|c|}{ Đốc Phụng 12 giờ sau xử lý mặn } & \multicolumn{3}{|c|}{ Nếp Mõ̃ 12 giờ sau xử lý mặn } \\
\hline Mã số gien & Tên gien & Giảm & Mã số gien & Tên Gien & tăng \\
\hline LOC_Os02g38392 & & Os02g0597300 & LOC_Os01g62600 & OsLAC6 & Os01g0843800 \\
\hline LOC_Os02g45420 & OsERF\#020 & Os02g0676800 & LOC_Os02g43330 & HOX24 & Os02g0649300 \\
\hline LOC_Os02g45450 & OsDREB1G & Os02g0677300 & LOC_Os04g28520 & OsRALF-2 & Os04g0353600 \\
\hline LOC_Os03g08310 & TIFY11A & Os03g0180800 & LOC_Os04g33920 & Pd6 & 5800 \\
\hline LOC_Os03g08330 & OsJAZ4 & Os03g018 & LOC_Os05g31670 & AWr & 1400 \\
\hline LOC_Os03g52410 & & Os03g0734500 & LOC_Os05g46480 & OsLEA3-1 & 2500 \\
\hline LOC_Os04g40630 & & 0482300 & LOC_Os06g21250 & & 17400 \\
\hline LOC_Os06g03670 & OsDREB1C & Os06g0127100 & LOC_Os07g19000 & & Os07q \\
\hline LOC_Os07g48280 & & Os07g0680600 & LOC_Os11g42220 & OsLAC24 & Os11g0641800 \\
\hline LOC_Os08g36920 & DERF3 & Os08g0474000 & & & \\
\hline
\end{tabular}




\section{KẾT LUẬN VÀ ĐỀ XUẤT}

Tóm lại, phản ứng của giống lúa Đốc Phụng khi gặp tác động của stress mặn ở giai đoạn sớm thì hầu hết nhóm gien biểu hiện đều liên quan quan đến phản ứng kích thích stress và chủ yếu là nhóm gien yếu tố phiên mã và các gien này biểu hiện lại giảm hơn so với đối chứng. Trong khi giống lúa nêp Mỡ thể hiện phản ứng lại stress mặn chủ yếu ở các gien liên quan đến quá trình sinh học. Kết quả này cho thấy giống chống chịu mặn Đốc Phụng khi gặp stress mặn sẽ được các yếu tố phiên mã như họ gien OsDREB tiếp nhận tín hiệu ở giai đoạn sớm và giúp cây trồng chống chịu lại mặn. Vâng họ gien $O S D R E B$ là yếu tố phiên mã liên kết vào vùng promoter cis- AGCCGCC, được gọi là hộp GCC, kích hoạt sự phiên mã gien $P 5 S C$ và gien này là enzyme giúp tăng khả năng tích lũy proline trong cây.

\section{LÒ̀I CẢM TẠ}

Nghiên cứu được tài trợ bởi dự án Nâng cấp Trường Đại học Cần Thơ VN14-P6 (vốn vay ODA từ Chính phủ Nhật Bản). Chân thành cám ơn GS. TS. Tetsuya Yamada đã chỉ dẫn phân tích số liệu và GS. TS. Yuji Kishima đã hỗ trợ thiết kế thí nghiệm.

\section{TÀI LIẸU THAM KHẢO}

Bloom, J.S., Khan, Z., Kruglyak, L., Singh, M., \& Caudy, A.A. (2009). Measuring differential gen expression by short read sequencing: quantitative comparison to 2-channel gen expression microarrays. BMC Genomics, 10, 221. 10.1186/1471-2164-10-221

Bolser, D., Staines, D.M., Pritchard, E., \& Kersey, P. (2016). Ensembl Plants: Integrating Tools for Visualizing, Mining, and Analyzing Plant Genomics Data. In: Edwards D, ed. Plant Bioinformatics: Methods and Protocols. New York, NY: Springer New York, 115-140.

Chandran, A.K.N., Kim, J-W., Yoo, Y-H., Park, H.L., Kim, Y-J., Cho, M-H., \& Jung, K-H. (2019). Transcriptome analysis of rice-seedling roots under soil-salt stress using RNA-Seq method. Plant Biotechnology Reports 13, 567578. 10.1007/s11816-019-00550-3

Chen. S., Zhou, Y., Chen, Y., \& Gu, J. (2018). Fastp: an ultra-fast all-in-one FASTQ preprocessor. Bioinformatics 34, i884-i890. 10.1093/bioinformatics/bty560

Hussain, S., Zhu, C., Bai, Z., Huang, J., Zhu, L., Cao, X., Nanda, S., Hussain, S., Riaz, A., Liang, Q., Wang, L., Li, Y., Jin, Q., \& Zhang, J. (2019). iTRAQ-Based Protein Profiling and Biochemical Analysis of Two Contrasting Rice Genotypes Revealed Their Differential Responses to Salt
Stress. International journal of molecular sciences 20, 547. 10.3390/ijms20030547

Kawahara, Y., de la Bastide, M., Hamilton, J.P., Kanamori, H., McCombie, W.R., Ouyang, S., Schwartz, D.C., Tanaka, T., Wu, J., Zhou, S., Childs, K.L., Davidson, R.M., Lin, H., QuesadaOcampo, L., Vaillancourt, B., Sakai, H., Lee, S.S., Kim, J., Numa, H., Itoh, T., Buell, C.R., \& Matsumoto, T. (2013). Improvement of the Oryza sativa Nipponbare reference genome using next genration sequence and optical map data. Rice (New York, NY) 6, 4-4. 10.1186/19398433-6-4

Keel, B.N., \& Snelling, W.M. (2018). Comparison of Burrows-Wheeler Transform-Based Mapping Algorithms Used in High-Throughput WholeGenome Sequencing: Application to Illumina Data for Livestock Genomes. Frontiers in gentics 9, 35-35. 10.3389/fgen.2018.00035

Kim, D., Langmead, B., \& Salzberg, S.L. (2015). HISAT: a fast spliced aligner with low memory requirements. Nature methods 12, 357-360. 10.1038/nmeth.3317

Li, H. (2011). A statistical framework for SNP calling, mutation discovery, association mapping and population gentical parameter estimation from sequencing data. Bioinformatics 27, 29872993. 10.1093/bioinformatics/btr509

Li, H., Handsaker, B., Wysoker, A., Fennell, T., Ruan, J., Homer, N., Marth, G., Abecasis, G., Durbin, R., \& Genome Project Data Processing, S. (2009). The Sequence Alignment/Map format and SAMtools. Bioinformatics (Oxford, England) 25, 2078-2079. 10.1093/bioinformatics/btp352

Li, Y-F., Zheng, Y., Vemireddy, L.R., Panda, S.K., Jose, S., Ranjan, A., Panda, P., Govindan, G., Cui, J., Wei, K., Yaish, M.W., Naidoo, G.C., \& Sunkar, R. (2018). Comparative transcriptome and translatome analysis in contrasting rice genotypes reveals differential mRNA translation in salttolerant Pokkali under salt stress. BMC genomics 19, 935-935. 10.1186/s12864-018-5279-4

Liao, Y., Smyth, G.K., \& Shi, W. (2014). FeatureCounts: an efficient genral purpose program for assigning sequence reads to genomic features. Bioinformatics (Oxford, England) 30, 923-930. 10.1093/bioinformatics/btt656

Love, M.I., Huber, W., \& Anders, S. (2014). Moderated estimation of fold change and dispersion for RNA-seq data with DESeq2. Genome biology 15, 550-550. 10.1186/s13059014-0550-8

Moon, S. J., Min, M. K., Kim, J., Kim, D. Y., Yoon, I. S., Kwon, T. R., ... \& Kim, B. G. (2019). Ectopic expression of OsDREB1G, a member of the OsDREB 1 subfamily, confers cold stress 
tolerance in rice. Frontiers in plant science, 10, 297. 10.3389/fpls.2019.00297

Shinozaki, K., \& Yamaguchi-Shinozaki, K. (2006). Gen networks involved in drought stress response and tolerance. Journal of Experimental Botany 58, 221-227. 10.1093/jxb/erl164

Tam, N.T. (2019). The genome constitution of rice resources in the Mekong Delta and their association with salinity stress (Doctoral dissertation). Hokkaido University.

Tian, T., Liu, Y., Yan, H., You, Q., Yi, X., Du, Z., ... \& $\mathrm{Su}$, Z. (2017). agriGO v2. 0: a GO analysis toolkit for the agricultural community, 2017 update. Nucleic acids research, 45(W1), W122-W129.

VNDMA. (2020). Báo cáo thông kê thiệt hại do thiên tai năm 2020 (truy cập ngày 27 tháng 07 năm 2020).

USDA. (2018). Grain World Markets and Trade report.
Wang, J., Zhu, J., Zhang, Y., Fan, F., Li, W., Wang, F., Zhong, W., Wang, C., \& Yang, J. (2018). Comparative transcriptome analysis reveals molecular response to salinity stress of salttolerant and sensitive genotypes of indica rice at seedling stage. Scientific reports 8, 2085-2085. 10.1038/s41598-018-19984-w

Wang, Q., Guan, Y., Wu, Y., Chen, H., Chen, F., \& $\mathrm{Chu}$, C. (2008). Overexpression of a rice OsDREB $1 F$ gen increases salt, drought, and low temperature tolerance in both Arabidopsis and rice. Plant Molecular Biology 67, 589-602. 10.1007/s11103-008-9340-6

Zhou, Y., Yang, P., Cui, F., Zhang, F., Luo, X., \& Xie, J. (2016). Transcriptome Analysis of Salt Stress Responsiveness in the Seedlings of Dongxiang Wild Rice (Oryza rufipogon Griff.). PLOS ONE 11, e0146242.

10.1371/journal.pone.0146242 